PJOHS

José Florencio F. Lapeña, Jr., MA, MD

Department of Otorhinolaryngology College of Medicine, University of the Philippines Manila, Philippines

Department of Otorhinolaryngology Head and Neck Surgery

East Avenue Medical Center, Diliman

Quezon City, Philippines

\section{A Dozen Years, A Dozen Roses}

Twelve years have passed since my first editorial for the Philippine Journal of Otolaryngology Head and Neck Surgery, on the occasion of the silver anniversary of our journal and the golden anniversary of the Philippine Society of Otolaryngology - Head and Neck Surgery (PSO-HNS). ${ }^{1}$ Special editorials have similarly marked our thirtieth (pearl) ${ }^{2}$ and thirty-fifth (coral or jade) ${ }^{3}$ journal anniversaries, punctuating editorials on a variety of themes in between. Whether they were a commentary on issues and events in the PSO-HNS or Philippine Society, or on matters pertaining to medical research and writing, publication and peer review, I have often wondered whether my words fell on deaf ears. But write, must l-- despite my writer's doubt.

What then, do a dozen years symbolize? As a baby boomer, I am all too familiar with what "cheaper by the dozen" meant in daily life, outwardly displayed in the matching attire my siblings and I wore on special occasions -- such as Yuletide when we would sing the carol "twelve days of Christmas." We read the comedy "Twelfth Night" in school, although I admittedly enjoyed "The Dirty Dozen" ${ }^{\prime \prime}$ more than Shakespeare. College ROTC introduced me to the "Daily Dozen" and the grueling Navy count- 1,2,3, ONE! One, two, three, TWO! (One, two, three, four! I love the Marine Corps!) And that is as far as my list of memorable dozens goes, covering five dozen years of life.

Of these, one fifth or $20 \%$ of my life has been devoted to our journal. From that perspective, I cannot help but wonder whether, or how it mattered. After 12 years, the day-to-day routine has hardly changed; neither have the periodic problems that precede the birth of each issue. I still find it difficult to solicit and follow-up reviews, and I still burn the midnight oil on weekends and holidays, patiently guiding authors in revising their manuscripts. Nevertheless, our journal has come a long way from where it was when we started (although it has not reached as far and as quickly as I would have wanted it to). Much depends on our authors and the caliber of their contributions, and our reviewers and the quality and timeliness of their reviews. However, despite our efforts to conduct education and training sessions on Medical Writing and Peer Review, the new batch of submissions and reviews each year evinces the need to repeat these regularly. In this regard, the increasing response-ability of our associate editors and continuing support of our society are needed to ensure our progress.

This year, we welcome Dr. Eris Llanes as our new Managing Editor as we thank and congratulate Dr. Tony Chua (who retains his position as Associate Editor) for serving in that role for the past 12 years. We have finally migrated from our previous platform to the Public Knowledge Platform - Open Journal Systems (PKP-OJS) available from https://pjohns.pso-hns.org/index.php/pjohns/ index. The PSO-HNS has become a member of the Publishers International Linking Association 
(PILA), which manages and maintains, deposits and retrieves, Metadata and Digital Identifiers inclusive of associated software and know-how. This will enable us to register Digital Object Identifiers (DOIs) for all our content using the Crossref system (https://www.crossref.org/about/), making our "research outputs easy to find, cite, link, and assess."7 We are also subscribing to the Crossref Similarity Check plagiarism detection software service powered by iThenticate ${ }^{\circ}$ (https://www.crossref. org/services/similarity-check// $)^{7}$ and are exploring ways and means of converting all our articles to eXtensible Markup Language (XML) format. These steps reflect our continuing efforts to comply with the requirements for indexing in the Directory of Open Access Journals $(D O A J)^{8}$ and our re-application for indexing in Scopus ${ }^{\circ}{ }^{9}$ These steps would not have been possible without the full support of the PSOHNS Board of Trustees under the leadership of our President, Dr. Aggie Remulla, for which we are truly grateful.

But these steps are just the beginning of a new journey, marking the next stage in the evolution of our journal. Now that we have embarked on it, we cannot stop to rest. Full activation of our Crossref ${ }^{\circledast}$ Similarity Check plagiarism detection software service is contingent upon migrating all our content from 1981 to the new system and generating DOls for each and every published article. Converting each article to XML format entails time, effort, and expertise. All these require that adequate resources be allocated to ensure that the migration and conversion not only starts as soon as possible, but continues in a regular, uninterrupted, and timely manner. Our efforts to teach authors to engage in relevant research and report these in writing, train reviewers to constructively critique manuscripts and uphold the soundness of the science, and tutor editors and mentors to oversee the publication process and produce a journal worth sharing, should be matched measure for measure by the management processes required for the journal to be securely indexed and widely disseminated on multiple platforms. These processes must be assured by the PSO-HNS as publisher of our journal.

Like it or not, our journal, and the contents we publish will long outlive us and our society. Nay, the PJOHNS will ensure that we who are published, and our PSO-HNS, will live on in the minds and hearts of our present and future readers - generations of medical students, residents and fellows, clinicians and academicians, scientists and researchers, public servants and policy-makers -- and through their healing hands, in the lives of their patients and publics. Cycles in perpetuity-- this is why we engage in relentless pursuit of excellence in publishing our journal, why we unceasingly strive for inclusion in DOAJ and Scopus, SCIE and MEDLINE (PubMed), and why we plead for your continuing support: to perpetuate your work that others may be informed of what has transpired, that by being inspired, they may transform others and the world they live in.

Indeed, the past 12 years may represent a complete cycle (such as 12 hours on a clock, or months in a year, or 12 signs of the zodiac), the first steps in the rebirth of our journal. Although they may not count among the "memorable dozens" of my life, each of these years may be likened to a rose (with its attendant thorns) - a bouquet of a dozen roses that I offer to all of you.

\author{
"for there's no rose without a thorn, \\ no night without the morn, \\ no gain without some meaningful loss ..."10
}

\footnotetext{
REFERENCES

1. Lapeña JF. Silver and gold: looking back, looking ahead. Philipp J Otolaryngol Head Neck Surg 2006 Dec; 21(1\&2):4

2. Lapeña JF.CreativeConcretions, Pearls and Publication:The Philippine Journal of Otolaryngology Head and Neck Surgery on its Thirtieth Year. Philipp J Otolaryngol Head Neck Surg 2011 Jul-Dec; 26 (2):4.

3. Lapeña JF. "Blood and Foliage: Coral Red and Jade Green" Philipp J Otolaryngol Head Neck Surg 2016 Jan-Jun; 31(1):4-5.

4. The twelve days of Christmas [music]: traditional / arranged by Frederic Austin (1872-1952) Printed 1909 London: Novello, 11p. [cited 31 October 2018] Available from: https://trove.nla. gov.au/work/10813839.

5. Shakespeare W. Twelfth Night. Complete Works of William Shakespeare. [Public Domain]
}

Created by Jeremy Hylton [cited 31 October 2018] Available from: http://shakespeare.mit.edu/ twelfth night/index.html.

6. The Dirty Dozen [motion picture]: directed by Robert Aldrich. UK/USA: M.K.H. Productions, Metro-Goldwyn-Mayer, 1967. [cited 31 October 2018] Catalogued at: https://catalog.afi.com/ Catalog/MovieDetailsPrintView/23682

7. Crossref. [cited 30 October 2018] Available from: https://www.crossref.org.

8. Directory of Open Access Journals. [cited 30 October 2018] Available from: https://doaj.org

9. Scopus . [cited 30 October 2018] Available from: https://www.elsevier.com/solutions/scopus.

10. "With Every Blessing, There's a Cross." [music and lyrics]: Jose Florencio F. Lapeña, Jr., 1983 (unpublished). 